\title{
Çerçeve Tipi Betonarme Binalarda Zemin Kat Yüksekliği Etkileri ve Maliyet
} Analizi

\author{
*1'Zehra Şule Garip \\ ${ }^{* 1}$ Faculty of Engineering, Department of Civil Engineering Karabuk University, Turkey
}

\section{Özet}

$\mathrm{Bu}$ çalışmada, farklı iki deprem tasarım sınıfı dikkate alınarak yeterli dayanımda tasarlanan deprem etkisindeki betonarme bina modellerinde zemin kat yüksekliğinin yapı davranışına ve kaba yapı maliyetine etkileri araştırılmıştır. Bu amaçla, betonarme bina modellerinde kat sayıları ve farklı zemin kat yükseklikleri parametre olarak dikkate alınmıştır. Çerçeve tipi betonarme bina modellerin dinamik analizleri Sta4Cad bilgisayar paket programında gerçekleştirilmiştir. Dinamik analizlerden elde edilen sonuçlar TS500-2000 ve TBDY2018'e göre değerlendirilmiştir. Betonarme bina modellerinin göreli kat ötelemeleri, ikinci mertebe etkileri ve maliyet hesabı değerleri tablo ve şekillerle sunulmuştur. Zemin kat yüksekliğinin artması göreli kat ötelemeleri arttırırken, kat sayısının da göreli kat ötelemelerinde etkili olduğu görülmüş̧ür.

Anahtar Kelimeler: Zemin kat, deprem tasarım sınıf1, kaba yapı maliyeti, betonarme

\begin{abstract}
In this study, the effects of ground floor height on building behavior and rough construction cost are investigated in earthquake-affected reinforced concrete building models designed with sufficient strength taking into account different earthquake design classes. For this purpose, floor numbers and different ground floor heights are considered as parameters in reinforced concrete building models. Dynamic analysis of frame-type reinforced concrete building models is carried out in the Sta4Cad computer package program. The result obtained from dynamic analyses is evaluated according to TS5002000 and TBDY2018. The relative floor displacements, second-order effects and cost calculation values of reinforced concrete building models are presented in tables and figures. While the increase in ground floor height increased relative floor displacements, the number of stories was also found to be effective in relative floor displacements.
\end{abstract}

Key words: Ground floor, earthquake design class, rough construction cost, reinforced concrete

\section{Giriş}

Ülkemiz deprem kuşağında yer almaktadır ve güncel depremler can ve mal kayıplarına neden olmuştur. Yakın geçmiş depremleri değerlendirildiğinde yapıların zemin kat yüksekliklerinin diğer katlardan fazla olması nedeniyle yapıda B2 yumuşak kat düzensizliklerinin meydana geldiği görülmüştür. Bu nedenle yapılarda ciddi hasarlar meydana gelmiş ya da bu hasarlar zemin katın çökmesi ile sonuçlanmıştır. Betonarme binalarda genel olarak üst katlar konut olarak kullanılırken zemin kat ticari amaçla kullanılmaktadır. Bu nedenle yapı tasarımında zemin kat yüksekliği değişkenlik arz etmektedir.

Bu hususlar dikkate alındığında zemin kat yüksekliğinin kademeli arttırılarak yapılarda meydana

*Corresponding author: Address: Faculty of Engineering, Department of Civil Engineering Karabuk University, 78050, Karabuk TURKEY. E-mail address: zsulegarip@ karabuk.edu.tr, Phone: +903704187057 
gelecek etkilerin araştırılması ve maliyet durumunun ortaya konulması hedeflenmiştir. Ayrıca betonarme binalarda zemin kat yüksekliğinin kat sayısına göre yapıda meydana getireceği etkiler değerlendirilmiştir. Çalışma kapsamında TBDY2018 [1]. ve TS500-2000 [2].ile belirtilen kriterler dikkate alınmış ve kıyaslama yapılmıştır.

Deprem tasarım sınıflarına göre yapılara etkiyen yatay spektral ivme değerleri değişiklik gösterdiği için çalışma kapsamında iki farkı deprem tasarım sınıfı dikkate alınmıştır. Spektral ivme değerlerine göre yapıda meydana gelecek maliyet etkileri incelenmiştir.

Literatürde, bugüne kadar yapılan çalışmalarda yumuşak kat düzensizliği ve zemin kat yüksekliği etkileri çeşitli analiz yöntemleri ile incelenmiştir. Günümüzde yürürlükte olan deprem yönetmeliği dikkate alınarak gerçekleştirilen fazla bir çalışmaya rastlanılmamıştır. [3-7].

\section{Analizlerde Kullanılan Parametreler}

\subsection{Deprem Parametreleri}

$\mathrm{Bu}$ çalışmada konut tipi betonarme bina modellerinin taşıyıcı sistemi çerçeveli sistem olarak modellenmiştir. Zemin kat yüksekliğinden dolayı meydana gelecek etkileri değerlendirebilmek için bina modeli için iki farklı konum belirlenmiştir. DTS1 sınıfı için İstanbul, DTS4 sınıfı için Karaman ili tercih edilmiştir.

Betonarme bina modelinin analizlerinde kullanılan deprem tasarım sınıfları için gerekli olan spektral ivme katsayıları, ZC zemin sınıfında Türkiye Deprem Tehlike haritasından elde edilmiştir ve Tablo 1 de sunulmuştur [8].

Tablo 1. Analizlerde kullanılmak üzere seçilen konumların spektral değerleri.

\begin{tabular}{|c|c|c|c|c|c|c|c|}
\hline \multirow{2}{*}{ DTS } & $\begin{array}{c}\text { Seçilen } \\
\text { İl }\end{array}$ & $\begin{array}{c}\text { Enlem } \\
\text { Boylam }\end{array}$ & $\begin{array}{c}\boldsymbol{S}_{\boldsymbol{S}} \\
\boldsymbol{S}_{\mathbf{1}}\end{array}$ & $\begin{array}{c}\boldsymbol{F}_{\boldsymbol{S}} \\
\boldsymbol{F}_{\mathbf{1}}\end{array}$ & $\begin{array}{c}\boldsymbol{S}_{\boldsymbol{D} \boldsymbol{S}} \\
\boldsymbol{S}_{\boldsymbol{D} \mathbf{1}}\end{array}$ & $\begin{array}{c}\boldsymbol{P}_{\boldsymbol{G A}} \\
\boldsymbol{P}_{\boldsymbol{G} \boldsymbol{V}}\end{array}$ & $\begin{array}{c}\boldsymbol{T}_{\boldsymbol{A}} \\
\boldsymbol{T}_{\boldsymbol{B}}\end{array}$ \\
\hline \multirow{2}{*}{ DTS1 } & \multirow{2}{*}{ İstanbul } & 40.754580 & 1.659 & 1.200 & 1.991 & 0.674 & 0.068 \\
& & 30.390230 & 0.454 & 1.500 & 0.681 & 55.630 & 0.342 \\
\hline \multirow{2}{*}{ DTS4 } & \multirow{2}{*}{ Karaman } & 37.179208 & 0.234 & 1.300 & 0.304 & 0.104 & 0.058 \\
& & 33.219810 & 0.059 & 1.500 & 0.089 & 5.209 & 0.291 \\
\hline
\end{tabular}

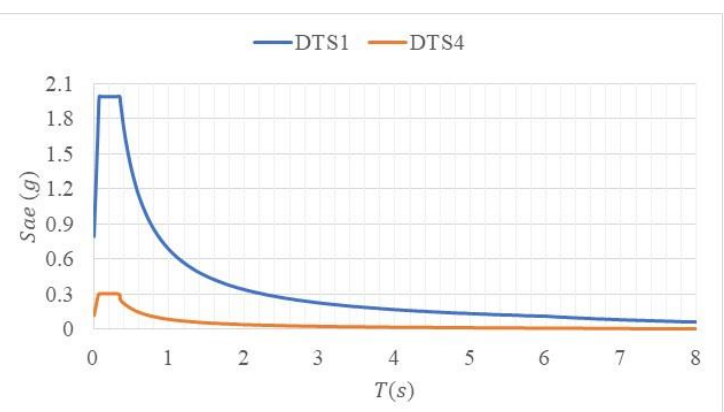

Şekil 1. Deprem Yer Hareketi Düzeylerine ait Yatay Elastik Tasarım Spektrumu 


\subsection{Betonarme Bina Bilgileri}

Betonarme bina modellerinin Sta4Cad bilgisayar paket programı ile dayanıma göre tasarımı gerçekleştirilmiş ve Kontrollü Hasar performans hedefini sağlayacak şekilde mod süperpozisyonu ile dinamik analizleri gerçekleştirilmiştir [9]. Betonarme bina modellerinin tasarımında dikkate alınan genel bilgiler Tablo 2 de verilmiştir.

Tablo 2. Analizlerde kullanılan genel bilgiler.

\begin{tabular}{|c|c|c|c|c|}
\hline \multirow{2}{*}{\multicolumn{2}{|c|}{ Bina Yükseklik Sınıfı (BYS) }} & 4 katlı & 8 katlı & 12 katlı \\
\hline & & 7 & 6 & 5 \\
\hline \multirow{2}{*}{ Kiriş Boyutları (mm) } & DTS1 & $300 \times 500$ & $300 \times 600$ & $350 \times 600$ \\
\hline & DTS4 & $250 \times 450$ & $300 \times 550$ & $300 \times 600$ \\
\hline \multirow{2}{*}{\multicolumn{2}{|c|}{$\begin{array}{l}\text { Radye Temel Kalınlığı } \\
\text { Süneklik Düzevi Yüksek Tasıvıcı Sistem }\end{array}$}} & $400 \mathrm{~mm}$ & $800 \mathrm{~mm}$ & $1200 \mathrm{~mm}$ \\
\hline & & A11 & $R=8$ & $D=3$ \\
\hline \multicolumn{2}{|c|}{ Bina Önem Katsayısı (I) } & 1 & & \\
\hline \multicolumn{2}{|c|}{ Bina Kullanım Sinıfı (BKS) } & 3 & & \\
\hline \multicolumn{2}{|l|}{ Zemin Sinıfi } & \multicolumn{3}{|c|}{$\begin{array}{l}\text { ZC (Çok sıkı kum, çakı1 ve sert kil tabakaları veya ayrışmış, } \\
\text { çok çatlaklı zayıf kayalar) }\end{array}$} \\
\hline \multicolumn{2}{|l|}{ Beton Sinıfi } & \multicolumn{2}{|c|}{$\mathrm{C} 30 / 37$} & $30 \mathrm{Mpa}$ \\
\hline \multicolumn{2}{|l|}{ Donatı Sinıfi } & \multicolumn{2}{|l|}{ B420C } & $420 M p a$ \\
\hline \multicolumn{2}{|c|}{ Zemin Yatak Katsayısı $\left(\mathrm{kN} / \mathrm{m}^{3}\right)$} & \multicolumn{3}{|l|}{68647} \\
\hline
\end{tabular}

Çalışma kapsamında iki farklı deprem tasarım sınıfında inşa edilen betonarme bina modellerinde zemin kat yükseklik değişiminin yapının davranışı ve maliyeti üzerindeki etkilerinin araştırılması amaçlanmıştır. Bu amaçla aynı kat planına sahip betonarme bina modellerinde dört farklı zemin kat yüksekliği dikkate alınmıştır. Yapı kalıp planı simetrik olacak şekilde tasarlanmış ve A1 burulma düzensizliğinin önüne geçilmiştir (Şekil 2). Bina modellerinin isimlendirilmesinde kullanılan yöntem Şekil 2'de sunulmuştur.
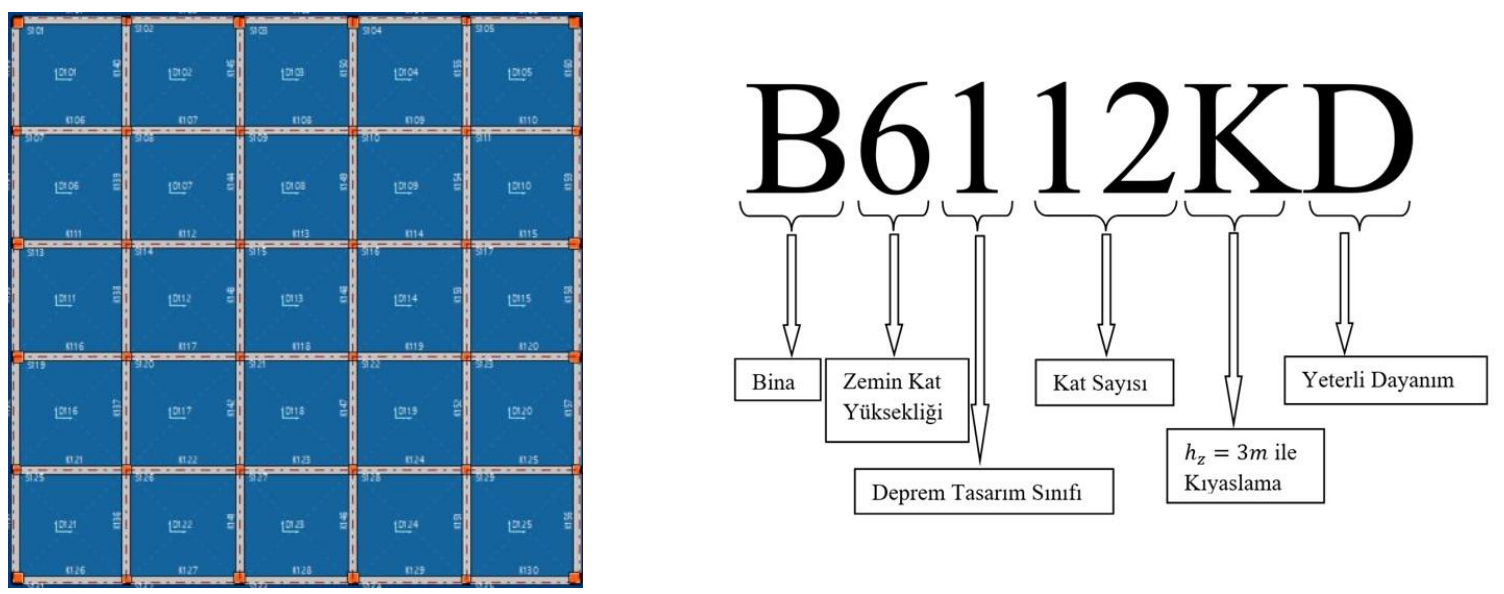

Şekil 2. Betonarme bina modeline ait kat planı ve isimlendirme şekli

Tüm modellerde zemin kat yüksekliği hariç kat yükseklikleri sabit ve $3 \mathrm{~m}$ dir. Zemin kat yüksekliği $3 \mathrm{~m}, 4 \mathrm{~m}, 5 \mathrm{~m}$ ve $6 \mathrm{~m}$ olarak tercih edilmiştir. Zemin kat yüksekliği $3 \mathrm{~m}$ baz alınarak diğer kat yüksekliklerinin etkileri belirlenmeye çalışılmıştır. Ayrıca çalışma kapsamında kat sayılarının 
davranışa etkilerini incelemek amacıyla üç farklı kat sayısı dikkate alınmıştır. Betonarme bina modelleri 4 katlı, 8 katlı ve 12 katlı olarak tasarlanmıştır ve Şekil 3 de sunulmuştur.

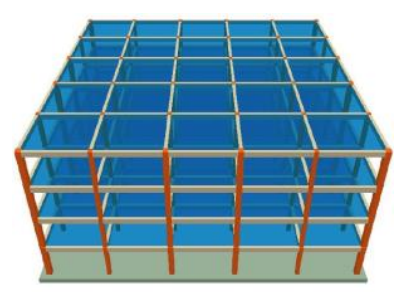

B314

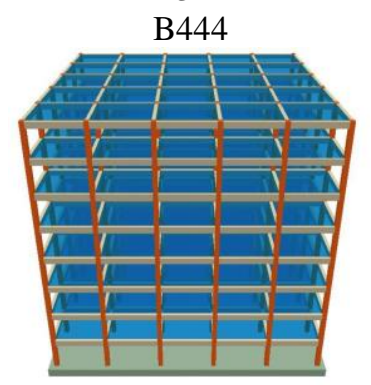

B318

B448

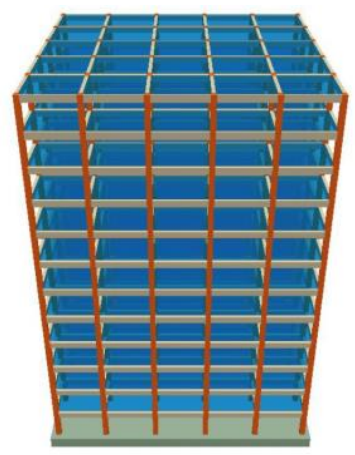

B3112

B4412

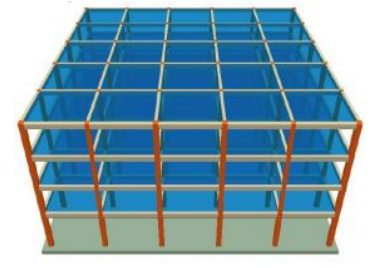

B414

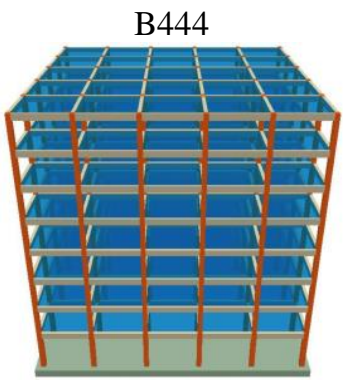

B418

B448

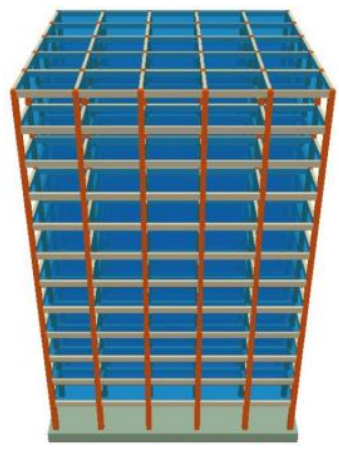

B4112

B4412

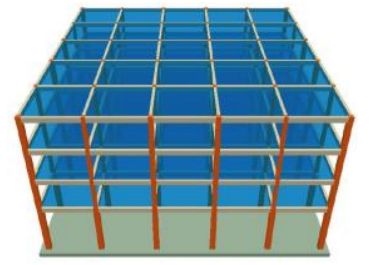

B514

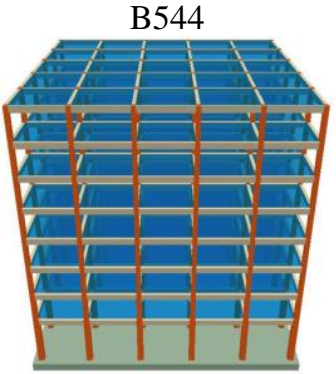

B518

B548

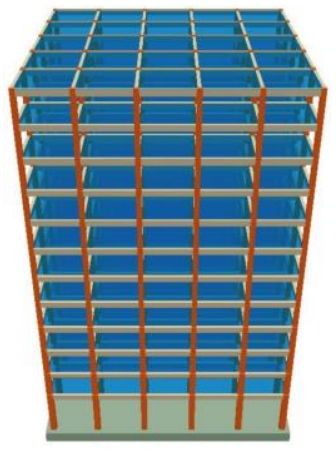

B5112

B5412

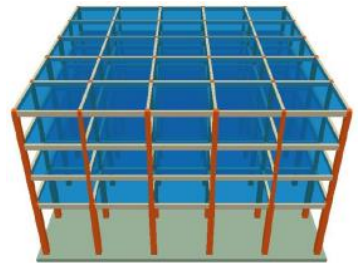

B614

B644

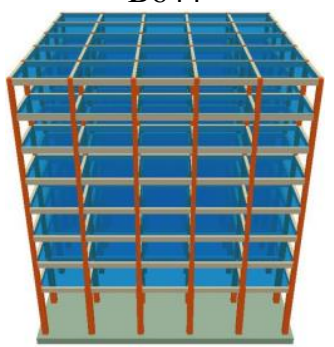

B618

B648

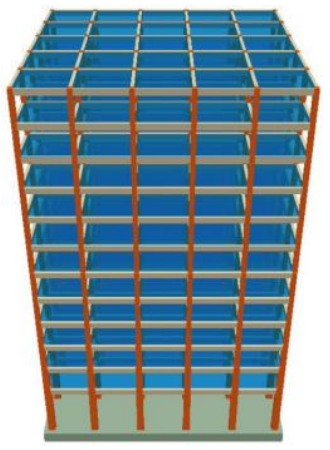

B6112

B6412

Şekil 3. Betonarme bina modellerine ait üç boyutlu görünümler

\section{Değerlendirmeler}

Betonarme bina modelleri tasarlanırken taşıyıcı sistemde yeterli dayanımı sağlayacak minimum kesit boyutları kullanılmıştır. Betonarme bina modelleri öncelikle $h_{z}=3 \mathrm{~m}$ için çözümlenmiş sonrasında diğer zemin kat yükseklikleri ile kıyaslama yapılmıştır. Yapılan analizlerde TS5002000 [2] Madde 7.6.2.1 de belirtilen şartın genel olarak sağlanmadığı görülmüş ve bu şartı sağlayacak şekilde taşıyıcı sistem elemanlarının boyutları arttırılmıştır. B2 yumuşak kat düzensizliği değerleri $\left(n_{k i}\right)$ incelendiğinde $\mathrm{B} 614 \mathrm{~K}$ bina modelinin haricinde düzensizlik oluşmamıştır. B614K bina modelinin $n_{k i}$ değerleri Tablo 3 de verilmiştir. 
Tablo 3. B614K bina modeline ait $n_{k i}$ rijitlik düzensizliği katsaylsl.

\begin{tabular}{ccccc} 
& \multicolumn{4}{c}{ Rijitlik Düzensizliği Katsayısı $\left(\boldsymbol{n}_{\boldsymbol{k} i}\right)$ değerleri } \\
B614K & X Yönü (+\%5) & X Yönü (-\%5) & Y Yönü $(+\% 5)$ & Y Yönü (-\%5) \\
\cline { 2 - 5 } 4 & 0.00 & 0.00 & 0.00 & 0.00 \\
3 & 1.71 & 1.71 & 1.74 & 1.74 \\
2 & 1.53 & 1.53 & 1.55 & 1.55 \\
1 & 2.02 & 2.02 & 2.02 & 2.02
\end{tabular}

TS500-2000 [2] de madde 7.6.2.1 ile yapı sistemi içinde yatay kuvvetlere karşı yeterli rijitliği sağlayacak düşey taşıyıcı elemanlar olması durumunda yatay ötelenmenin önlenmiş olduğu varsayılabileceği belirtilmektedir. İkinci mertebe çözümlemesi yapılamıyorsa, yapının herhangi bir katı için taşıyıcı sistemin bütünü göz önünde tutularak hesaplanan stabilite göstergesi denklem 1 ile belirtilen değeri aşmadığı durumlarda, o katta yeterli rijitlik bulunduğu ve yanal ötelenmenin önlenmiş olduğu varsayllabilmektedir.

$$
\varphi=1.5 \Delta_{i} \frac{\sum \frac{N_{d i}}{l_{f i}}}{V_{f i}} \leq 0.05
$$

Analizlerden elde edilen kolon alan oranları ve kat yanal ötelenme değerleri Tablo 4 ile sunulmuştur. DTS1 de inşa edilen 8 katlı yapılarda zemin kat yüksekliği $4 \mathrm{~m}$ ve $5 \mathrm{~m}$ yapılması durumunda kat yanal ötelenmeleri belirtilen sınır değeri aşmamıştır. Dolayısıyla kolon boyutlarında herhangi bir değişiklik yapılmamıştır. Ancak zemin kat yüksekliği $6 \mathrm{~m}$ olması durumunda kat yanal ötelenme değeri sınır değeri aşmış ve yanal stabiliteyi sağlamak için kolon boyutları arttırılmıştır. Diğer bina modelleri incelendiğinde zemin kat yüksekliğinin değişimi ile kat yanal ötelenme değerinin artış gösterdiği belirlenmiştir. Bu nedenle bu modellerde kolon boyutlarının artırılması yoluna gidilmiştir.

TBDY2018 de [1] madde 4.9.1.3 ile X ve Y deprem doğrultuları için bina katlarındaki etkin göreli kat ötelemelerinin kat içindeki en büyük değerinin sağlaması gereken iki koşul belirtilmiştir. Tablo 5 ile binada meydana gelen en büyük göreli kat öteleme değerleri verilmiş ve binaya ait sınır değer hesaplanarak sunulmuştur. Çalışma kapsamında bu madde üç adet bina modelinde sağlanamamıştır. DTS1 de tasarlanan 4 katlı zemin kat yüksekliği 5 ve 6 m ayrıca 12 katlı zemin kat yüksekliği $6 \mathrm{~m}$ olan bina modellerinde ortaya çıkan bu durum bina taşıyıcı sistem elemanlarının boyutlarının büyütülmesi ile giderilmiştir. DTS4 de tasarlanan bina modelleri bu koşulu sağlamaktadır.

TBDY2018 de [1] madde 4.9.2.2 ile tüm katlar için hesaplanan $\theta_{I I, i}^{X}{ }^{\prime}$ lerin maksimum değeri $\theta_{I I, \max }^{X}$ 'ın denklem 2 ile verilen koşulu sağlaması durumunda, ikinci mertebe etkilerinin tasarıma esas iç kuvvetlerin hesabında göz önüne alınmasının gerekli olmadığı belirtilmektedir. Ayrıca madde 4.9.2.2. ile belirtilen koşulun sağlanmaması durumunda tüm iç kuvvetlerin denklem 3 ile verilen ikinci mertebe büyütme katsayısı $\beta_{I I}^{X}$ ile çarpılarak arttırılacağı belirtilmektedir. $C_{h}$ taşıyıcı sistemin doğrusal olmayan histerik davranışına bağlı bir katsayıdır ve betonarme binalar için $C_{h}=$ 0.5 dir. Tasarlanan bina modellerinin ikinci mertebe gösterge değerleri için sınır değer 0.09 olarak hesaplanmıştır. Bina modellerine ait en büyük ikinci mertebe gösterge değerleri Tablo 5 ile sunulmuş ve tüm modellerin hesaplanan sınır değerin altında bir değer aldığı belirlenmiştir. Bu 
madde 1şı̆̆ında betonarme bina modellerinde herhangi bir rijitlik ve/veya dayanım artışına gidilmesinin gerekli olmadı̆̆ görülmektedir.

$$
\begin{aligned}
& \theta_{I I, \text { max }}^{X} \leq 0.12 \frac{D}{C_{h} R} \\
& \beta_{I I}^{X}=0.88+\frac{C_{h} R}{D} \theta_{I I, \text { max }}^{X} \geq 1
\end{aligned}
$$

Tablo 4. Bina modellerine ait kolon alan oranlart ve kat yanal ötelenme değerleri.

\begin{tabular}{llll|llll} 
Bina Adı & $\begin{array}{l}\boldsymbol{A}_{\boldsymbol{c}} / \boldsymbol{A}_{\boldsymbol{k}} \\
(\boldsymbol{\%})\end{array}$ & $\boldsymbol{\varphi}_{\boldsymbol{x}} \leq \mathbf{0 . 0 5}$ & $\boldsymbol{\varphi}_{\boldsymbol{y}} \leq \mathbf{0 . 0 5}$ & $\mathbf{B i n a}$ Adı & $\begin{array}{l}\boldsymbol{A}_{\boldsymbol{c}} / \boldsymbol{A}_{\boldsymbol{k}} \\
(\boldsymbol{\%})\end{array}$ & $\boldsymbol{\varphi}_{\boldsymbol{x}} \leq \mathbf{0 . 0 5}$ & $\boldsymbol{\varphi}_{\boldsymbol{y}} \leq \mathbf{0 . 0 5}$ \\
\hline B314 & 0.922 & 0.0286 & 0.0284 & $\mathbf{B 3 4 4}$ & 0.653 & 0.0448 & 0.032 \\
B414K & 0.922 & 0.0395 & 0.0388 & $\mathbf{B 4 4 4 K}$ & 0.653 & 0.0696 & 0.0585 \\
B414KD & 0.939 & 0.0366 & 0.036 & $\mathbf{B 4 4 4 K D}$ & 0.72 & 0.045 & 0.0316 \\
B514K & 0.922 & 0.0562 & 0.0554 & $\mathbf{B 5 4 4 K}$ & 0.653 & 0.0994 & 0.0951 \\
B514KD & 0.972 & 0.0447 & 0.0442 & $\mathbf{B 5 4 4 K D}$ & 0.781 & 0.0479 & 0.0329 \\
B614K & 0.922 & 0.0765 & 0.0756 & $\mathbf{B 6 4 4 K}$ & 0.653 & 0.1356 & 0.1341 \\
B614KD & 1.022 & 0.0491 & 0.0481 & $\mathbf{B 6 4 4 K D}$ & 0.85 & 0.05 & 0.0356 \\
& & & & & & & \\
B318 & 1.123 & 0.0372 & 0.0368 & $\mathbf{B 3 4 8}$ & 0.922 & 0.0441 & 0.0438 \\
B418K & 1.123 & 0.0371 & 0.0367 & $\mathbf{B 4 4 8 K}$ & 0.922 & 0.0661 & 0.0647 \\
B518K & 1.123 & 0.0399 & 0.0386 & $\mathbf{B 4 4 8 K D}$ & 0.952 & 0.0496 & 0.0432 \\
B618K & 1.123 & 0.052 & 0.0505 & $\mathbf{B 5 4 8 K}$ & 0.922 & 0.0954 & 0.0939 \\
B618KD & 1.137 & 0.0486 & 0.047 & $\mathbf{B 5 4 8 K D}$ & 1.055 & 0.0482 & 0.0375 \\
& & & & $\mathbf{B 6 4 8 K}$ & 0.922 & 0.1312 & 0.1297 \\
& & & & $\mathbf{B 6 4 8 K D}$ & 1.106 & 0.0496 & 0.0433 \\
B3112 & 1.281 & 0.0493 & 0.049 & $\mathbf{B 3 4 1 2}$ & 1.258 & 0.0499 & 0.0483 \\
B4112K & 1.281 & 0.0522 & 0.0518 & $\mathbf{B 4 4 1 2 K}$ & 1.258 & 0.0541 & 0.0519 \\
B4112KD & 1.312 & 0.05 & 0.0495 & $\mathbf{B 4 4 1 2 K D}$ & 1.322 & 0.0489 & 0.042 \\
B5112K & 1.281 & 0.0637 & 0.0617 & $\mathbf{B 5 4 1 2 K}$ & 1.258 & 0.0742 & 0.0719 \\
B5112KD & 1.369 & 0.0498 & 0.0494 & $\mathbf{B 5 4 1 2 K D}$ & 1.388 & 0.0494 & 0.0464 \\
B6112K & 1.281 & 0.0841 & 0.0821 & $\mathbf{B 6 4 1 2 K}$ & 1.258 & 0.0983 & 0.096 \\
B6112KD & 1.413 & 0.0497 & 0.049 & $\mathbf{B 6 4 1 2 K D}$ & 1.481 & 0.0499 & 0.0421 \\
Not: $A_{c} / A_{k}$, kolon alan & oranin ifade etmektedir. & & & &
\end{tabular}


Tablo 5. Bina modellerine ait maksimum etkin göreli kat ötelemeleri ve ikinci mertebe gösterge değerleri.

\begin{tabular}{|c|c|c|c|c|c|c|c|c|c|}
\hline Bina Adı & $\delta_{i, \max }^{(X)}$ & $\delta_{i, \max }^{(Y)}$ & Sinır & $\theta_{I I, \max }$ & Bina Adı & $\delta_{i, \text { max }}^{(X)}$ & $\delta_{i, \text { max }}^{(Y)}$ & Sinır & $\theta_{I I, \max }$ \\
\hline B314 & 0.0186 & 0.0186 & 227 & 0.0160 & B344 & 0.0032 & 0.0032 & 0.0215 & 0.0290 \\
\hline B414K & 0.0200 & 0.0199 & 0227 & 0.0230 & B444K & 0.0034 & 0.0034 & 0.0215 & 0.0400 \\
\hline B414KD & 0.0188 & 0.0187 & 0.0227 & 0.0210 & B444KD & 0.0032 & 0.0032 & 0.0215 & 0.0290 \\
\hline B514K & 0.0245 & 0.0243 & 0.0227 & 0.0320 & B544K & 0.0048 & 0.0048 & 0.0215 & 0.0570 \\
\hline B514KD & 0.0207 & 0.0206 & 0.0227 & 0.0260 & B544KD & 0.0031 & 0.0031 & 0.0215 & 0.0300 \\
\hline B614K & 0.0282 & 0.0281 & 0.0227 & 0.0440 & B644K & 0.0066 & 0.0065 & 0.0215 & 0.0770 \\
\hline B614KD & 0.0209 & 0.0207 & 0.0227 & 0.0280 & B644KD & 0.0030 & 0.0030 & 0.0215 & 0.0310 \\
\hline B318 & 0.0169 & 0.0169 & 7 & 0.0220 & B348 & 0.0030 & 0.0030 & 0.0215 & 0.0330 \\
\hline B418K & 0.0164 & 0.0163 & 0.0227 & 0.0220 & B448K & 0.0035 & 0.0034 & 0.0215 & 0.0410 \\
\hline B518K & 0.0156 & 0.0155 & 0.0227 & 0.0250 & B448KD & 0.0032 & 0.0031 & 0.0215 & 0.0350 \\
\hline B618K & 0.0180 & 0.0175 & 0.0227 & 0.0320 & B54 & 0.0050 & 0.0050 & 0.0215 & 0.0590 \\
\hline \multirow[t]{3}{*}{ B618KD } & 0.0167 & 0.0166 & 0.0227 & 0.0300 & B548KD & 0.0029 & 0.0029 & 0.0215 & 0.0300 \\
\hline & & & & & B648K & 0.0069 & 0.0069 & 0.0215 & 0.0810 \\
\hline & & & & & B648KD & 0.0030 & 0.0029 & 0.0215 & 0.0300 \\
\hline B3112 & 0.0194 & 0.0193 & 0.0227 & 0.0310 & B3412 & 0.0031 & 0.0031 & 0.0215 & 0.0340 \\
\hline B4112K & 0.0195 & 0.0194 & 0.0227 & 0.0330 & B4412K & 0.0033 & 0.0032 & 0.0215 & 0.0370 \\
\hline B4112KD & 0.0195 & 0.0193 & 0.0227 & 0.0310 & B4412KD & 0.0031 & 0.0031 & 0.0215 & 0.0330 \\
\hline B5112K & 0.0225 & 0.0219 & 0.0227 & 0.0400 & B5412K & 0.0040 & 0.0039 & 0.0215 & 0.0460 \\
\hline B5112KD & 0.0195 & 0.0194 & 0.0227 & 0.0310 & B5412KD & 0.0031 & 0.0031 & 0.0215 & 0.0320 \\
\hline B6112K & 0.0297 & 0.0291 & 0.0227 & 0.0530 & В6412K & 0.0053 & 0.0052 & 0.0215 & 0.0610 \\
\hline B6112KD & 0.0196 & 0.0194 & 0.0227 & 0.0310 & B6412KD & 0.0032 & 0.0031 & 0.0215 & 0.0310 \\
\hline
\end{tabular}

Maliyet hesabında Çevre ve Şehircilik Bakanlığı 2021 yılı İnşaat ve Tesisat Birim Fiyatları kullanılmıştır (Tablo 6). Beton sınıfı, ince demir, kalın demir ve kalıp birim fiyatları dikkate alınarak toplam maliyet hesaplanmıştır. [10]

Tablo 6. Çevre ve Şehircilik Bakanlı̆ğ 2021 yll inşaat ve tesisat birim fiyatları [10]

\begin{tabular}{|c|c|c|c|}
\hline Poz No & Poz Açıklaması & Birim & $\begin{array}{l}\text { Birim Fiyat } \\
(T L)\end{array}$ \\
\hline 15.150 .1006 & $\begin{array}{l}\text { Beton santralinde üretilen veya satın alınan ve beton } \\
\text { pompasıyla basılan, C30/37 basınç dayanım sınıfında, gri } \\
\text { renkte, normal hazır beton dökülmesi (beton nakli dahil) }\end{array}$ & $\mathrm{m}^{3}$ & 291.94 \\
\hline 15.160 .1003 & $\begin{array}{l}\text { Ø8-Ø12 mm nervürlü beton çelik çubuğu, çubukların } \\
\text { kesilmesi, bükülmesi ve yerine konulması }\end{array}$ & to & 7415.10 \\
\hline 15.160 .1004 & $\begin{array}{l}\emptyset 14-\varnothing 28 \mathrm{~mm} \text { nervürlü beton çelik çubuğu, çubukların } \\
\text { kesilmesi, bükülmesi ve yerine konulması }\end{array}$ & ton & 7354.10 \\
\hline 15.180 .1003 & Plywood ile düz yüzeyli betonarme kalıbı yapılması & $\mathrm{m}^{2}$ & 82.78 \\
\hline
\end{tabular}

Betonarme bina modellerinin DTS1 ve DTS4 için kaba yapı inşaat maliyetleri hesaplanmış ve DTS4 baz alınarak her bina için DTS1 de tasarlanması durumunda meydana gelecek maliyet farkları belirlenmiştir. DTS1 de meydana gelen maliyet artı̧̧ oranları Şekil 4 de sunulmuştur. Şekilden de görüldüğü gibi zemin kat yüksekliği artış eğilimi gösterdikçe DTS ler arasında ortaya 
çıkan maliyet farkı azalmaktadır. En yüksek maliyet farkının 4 katlı yapılarda oluştuğu görülmektedir. Dolayısıyla bina modellerinin kat sayılarının artışı ile DTS1 de meydana gelen maliyet artış oranı düşmektedir.

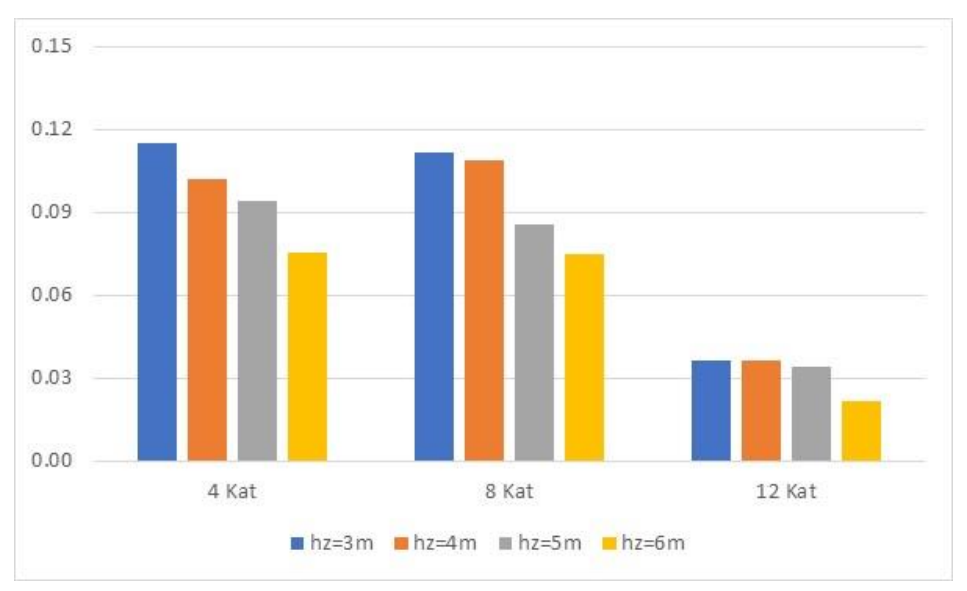

Şekil 4. DTS4 baz alınarak DTS1 de meydana gelen maliyet artışları

Betonarme bina modellerinde hesaplanan kaba yapı inşaat maliyet artış oranları $h_{z}=3 \mathrm{~m}$ baz alınarak DTS1 ve DTS4 için hesaplanmış ve Şekil 5 de sunulmuştur. Tüm bina modellerinde zemin kat yüksekliğinin artışı kaba yapı inşaat maliyetini arttırmaktadır. Kat sayısı arttıkça maliyet değerleri arasındaki fark azalmaktadır. Maliyet açısından DTS4 de tasarlanan bina modellerinde zemin kat yüksekliğine bağlı maliyet artışı DTS1 den daha fazladır.
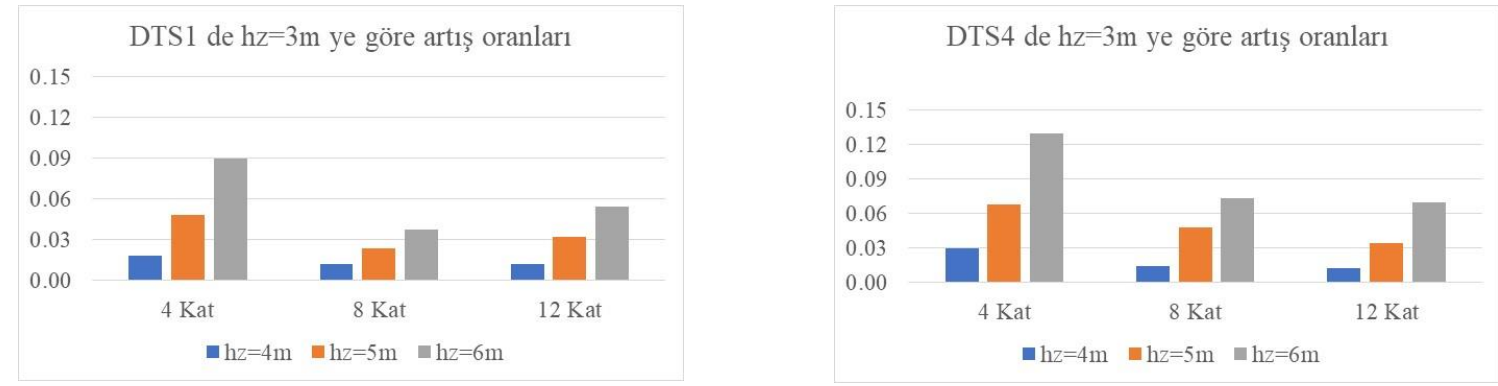

Şekil 5. $h_{z}=3 \mathrm{~m}$ baz alınarak DTS1 ve DTS4 de meydana gelen maliyet artış oranları

\section{Sonuçlar:}

Çalışma kapsamında tasarlanan betonarme bina modellerinin Sta4Cad bilgisayar paket programı ile dayanıma göre tasarımı ve dinamik analizleri gerçekleştirilmiştir. Analizlerden elde edilen veriler değerlendirildiğinde aşağıdaki sonuçlara varılmıştır.

1. B614K bina modeli haricinde yumuşak kat düzensizliğinin meydana gelmediği belirlenmiştir.

2. TS500-2000 de belirtilen kat yanal ötelenme değerinin B418K ve B518K bina modelleri 
haricinde zemin kat yüksekliğinin değişimi ile artış gösterdiği belirlenmiştir.

3. TBDY2018 de belirtilen maksimum etkin göreli kat ötelenmelerinin B514K, B614K ve B6112K bina modelleri haricinde sınır değerleri sağladığı belirlenmiştir.

4.TBDY2018 de belirtilen maksimum ikinci mertebe gösterge değerlerinin tüm bina modellerinde sınır değeri sağladığı görülmüştür.

5. DTS4 de tasarlanan bina modellerinde zemin kat yüksekliğine bağlı maliyet artışı DTS1 den daha fazladir.

6. Tüm bina modellerinde zemin kat yüksekliğinin artışı kaba yapı inşaat maliyetini arttırmaktadır.

\section{Teşekkür}

Bu çalışma kapsamında kullanılan Sta4Cad paket programının kullanım izni ve sağladıkları teknik destek dolayısıyla Sta Bilgisayar Mühendislik Müşavirlik Ltd. Şti.'ne teşekkürlerimi sunarım.

\section{Kaynaklar}

[1] TBDY2018, Türkiye Bina Deprem Yönetmeliği, Afet ve Acil Durum Yönetimi Başkanlığ1, Ankara, 1-395, 2018.

[2] TS500-2000., Betonarme Yapıların Tasarım ve Yapım Kuralları, Türk Standartları Enstitüsü Necatibey Caddesi, 112 Bakanlıklar/ANKARA

[3] D. Başl1, "2007 Deprem Yönetmeliği'ne göre Yapı Düzensizliğinin Betonarme Binaların Deprem Davranışlarına Olan Etkilerinin İncelenmesi", Yüksek Lisans Tezi, Çukurova Üniversitesi, Fen Bilimleri Enstitüsü, İnşaat Mühendisliği Anabilim Dalı, Adana, 2011

[4] T.O. Karasu, "Yumuşak Kat Düzensizliği Bulunan Betonarme Bir Yapının TDY 2007'ye Göre Performans Analizi", Yüksek Lisans Tezi, Celal Bayar, Fen Bilimleri Enstitüsü, İnşaat Mühendisliği Anabilim Dalı, Manisa, 2011

[5] M. Sayar, "Doğrusal Elastik Deprem Hesabı Yöntemlerinin Taban Kesme Kuvveti ve Göreli Kat Ötelemesi Açısından Karşılaştırılması", Yüksek Lisans Tezi, Gazi Üniversitesi, Fen Bilimleri Enstitüsü, İnşaat Mühendisliği Anabilim Dalı, Ankara, 2013

[6] Garip, Z., Ş., "Yumuşak kat düzensizliği olan betonarme binalarda yapı zemin etkileşimi”, 5th International Symposium on Innovative Technologies in Engineering and Science, Bakü ,10361045, (2017).

[7] Z. Ş. Garip, E. Eren, F. Erdem ve M. N. Bozdoğan, “Deprem Etkisindeki Betonarme Binalarda Yumuşak Kat Düzensizliğine Perde Duvar Etkisi," 5th International Symposium on Innovative Technologies in Engineering and Science (ISITES2017), Baku-Azerbaijan, 2017, ss. 449-556. 
[8] AFAD, T.C. İçişleri Bakanlığı Afet ve Acil Durum Yönetimi Başkanlı̆̆ı, Ankara, https://www.afad.gov.tr/turkiye-deprem-tehlike-haritasi, 2019.

[9] Sta4-CAD, "Structural analysis for computer aided design", ver.14. www.sta.com.tr, 2021.

[10] Yüksek Fen Kurulu Başkanlığı, T.C. Çevre ve Şehircilik Bakanlığı, İnşaat ve Tesisat Birim Fiyatları 2019, https://yfk.csb.gov.trl, Ankara, 2019. 